\title{
Government Medical Officers' Association's proposed COVID-19 Exit Strategy for Sri Lanka
}

Anuruddha Padeniya ${ }^{1,2}$, Samantha Ananda ${ }^{1,3^{*}}$, Nimani de Lanerolle ${ }^{1,3}$, Bhumini Karunarathna ${ }^{1,3}$, Naveen De Soysa ${ }^{1,4}$, Senal Fernando ${ }^{1,5}$, Haritha Aluthge ${ }^{1,3}$, Chandana Dharmaratna ${ }^{1,6}$, Sarada Kannangara ${ }^{1,7}$ Kiyara Fernando $^{1,8}$, Prasad Colombage ${ }^{1,9}$

${ }^{1}$ Government Medical Officers' Association (GMOA), Colombo, Sri Lanka; ${ }^{2}$ Lady Ridgeway Hospital Colombo, Sri Lanka; ${ }^{3}$ Ministry of Health, Sri Lanka; ${ }^{4}$ National Institute of Health Services, Ministry of Health, Sri Lanka; ${ }^{5}$ Base Hospital Homagama, Sri Lanka; ${ }^{6}$ Colombo South Teaching Hospital, Sri Lanka; ${ }^{7}$ Apeksha Hospital, Maharagama, Sri Lanka; ${ }^{8}$ University of Bristol Medical School, UK; ${ }^{9}$ National Eye Hospital, Sri Lanka

"Correspondence: samanthaananda@yahoo.com (iDhttps://orcid.org/0000-0002-9894-6982

DOI: https://doi.org/10.4038/jccpsl.v26i5.8328

Received on 9 May 2020

Accepted on 10 June 2020

\section{Summary}

Containment strategies for COVID-19 have varied across the globe. Sri Lanka made swift decisions and early interventions which were widely commended on a global platform. The Government Medical Officers' Association (GMOA) Sri Lanka proposed a strategy based on the World Health Organization's (WHO) four phases of the pandemic. This was a novel strategy based on real-time data and best available evidence. It facilitated three pillars: development of health and social capital via inter-sectoral collaboration, public engagement and government support. Advocacy by the GMOA was needed in terms of political leadership, health sector staff and the corporate sector to ensure smooth functioning at different levels.

Prolonged lockdown may be a short-term strategy. However, for low- and middle-income countries (LMIC) like Sri Lanka, this is not sustainable for a long period. This strategy focuses on resuming normal life and economic activity whilst maintaining citizen safety. The proposal is dynamic accounting for the reality of premature lifting of strict restrictions, which may result in a devastating 'second wave' of COVID-19 (1-2). The WHO recommends (3) a 'calibrated stepwise approach' as the most effective and safe means to ease limitations. This narrative report focuses on outlining the principles of the strategy and the reasoning behind it. 


\section{Public health response and its impact}

Following the detection of the first case, port of entry closure to prevent further entry of the virus was carried out. In addition, social distancing through school closure, public holidays, imposition of curfew, maintaining personal hygiene and respiratory etiquette was promoted. In order to ensure that behavioural changes necessitated due to COVID-19 took place, the basic concepts of health promotion were engaged. The GMOA too was involved in this endeavour by promoting healthy public policy and community participation, endorsing development of personal skills and ensuring that medical officers had a supportive environment to adjust to the necessary behavioural measures. Parallel to it, we focused on increasing the health capacity through staff training and low-cost innovation. To carry out these interventions, inter sectoral collaboration was beneficial. Since the implementation of an islandwide curfew-style lockdown on 20 March 2020, the GMOA has developed a potential transition strategy. This concept of the Exit Strategy was proposed to His Excellency the President on 4 April 2020 (Figure 1) and subsequently presented to the Presidential Task Force where the key stakeholder and the expert advisor the Ministry of Health was present (Figure 2). Presented here is a summary of the said strategy.

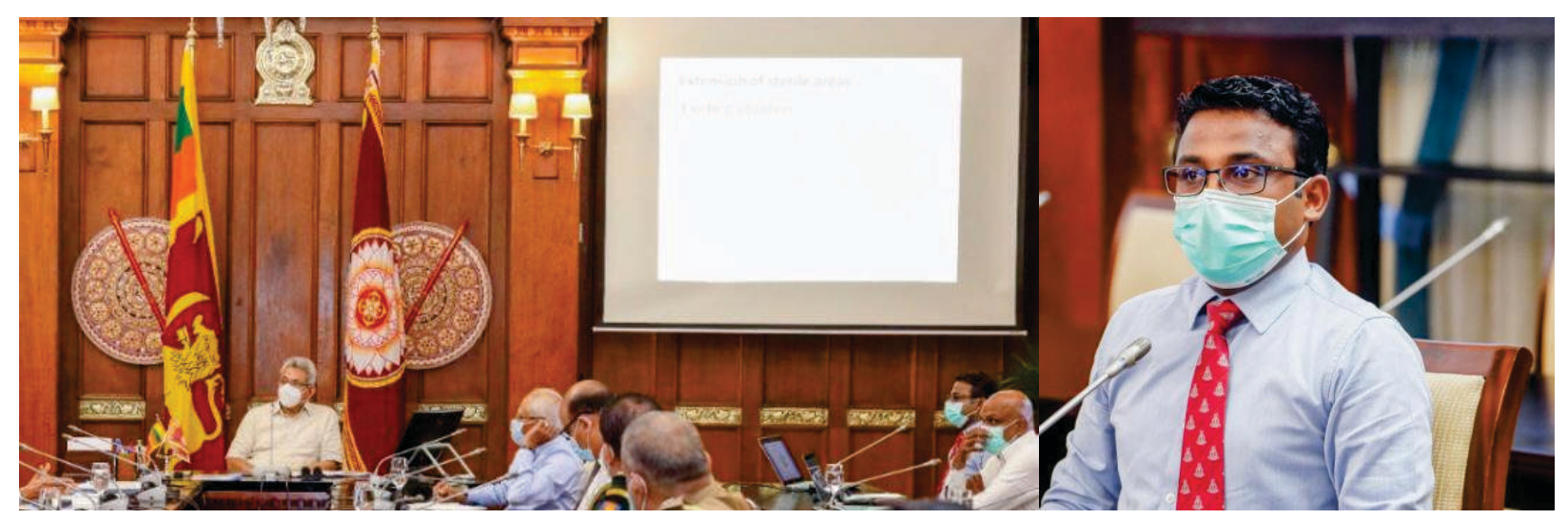

Figure 1: Exit Strategy presented to His Excellency the President

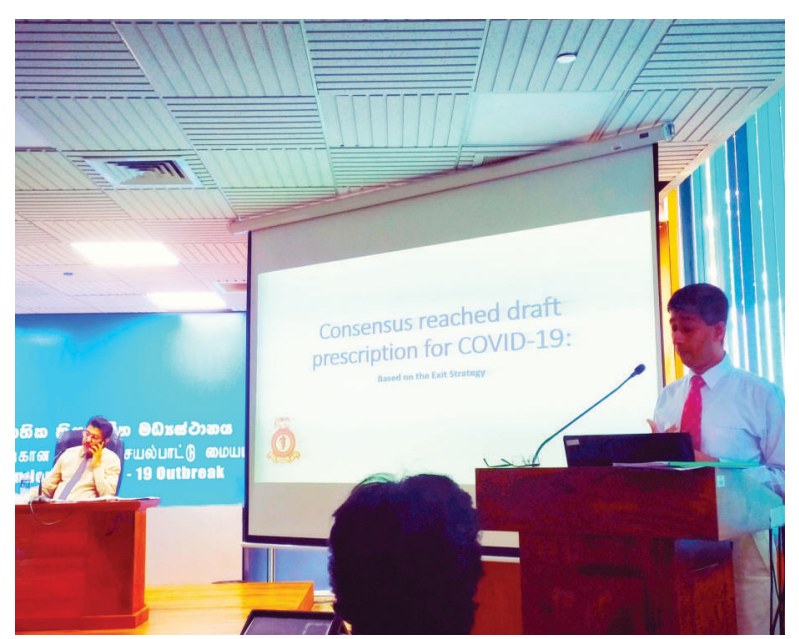

Figure 2: Presenting the Exit Strategy to His Excellency the President

\section{The strategy}

This strategy aims for a transition to near normal life while reduction of restriction on mobility realizing eradication or elimination of this virus on a global scale is not a possibility until an effective vaccine is developed. It considers the difficulty in assessing infectivity of the virus and the relatively poor sensitivity of currently available tests and considers the 'Hammer and the Dance' theory (4). It is based on the principles of governance of sterility in a surgical operating theatre (Figure 3). Three distinct zones are demarcated: 'contaminated', 'buffer' and 'sterile'. Based on extensive contact surveillance and case detection, identification of high-incidence areas will be done. The country is to be categorized into the 
above three zones based on criteria, with guidelines for 'governance' and 'border control' explored further.

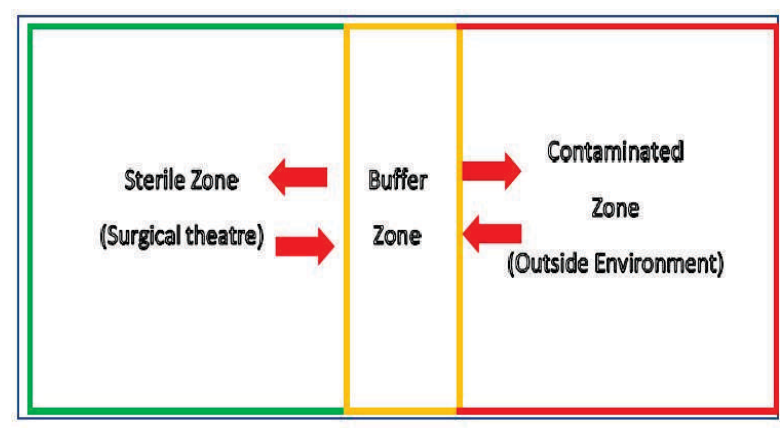

Figure 3: Concept based on surgical operating theatre setting

Presently, the 507 cases are clustered in 22 districts. Each district is categorised into smaller zones 'divisional secretariats' (DS), dividing the country into 331 well-demarcated zones. Each DS has representatives from ministries, banking services, hospital/medical care and other essential facilities. This allows each DS to function independently under the jurisdiction of the national government. This demarcation allows small subsections of the country to be given 'sterile', 'buffer' or 'contaminated' status, with targeted lockdowns limited to high-risk areas.

The zones will be allocated based on a weighted scoring system which was based on criteria, which included a matrix which considered not only health but social and economic aspects. The variables considered for each DS were the number of cases, number of those in quarantine, population density, number of clusters in the DS and certain other factors which would contribute to increased or decreased mobility such as number of healthcare facilities, number of petrol stations and supermarkets. Based on these variables, certain assumptions were identified such as the number of new cases during the last 14 days and having several clusters which would have a higher weightage. According to this scoring system, each DS could be identified as sterile, buffer or contaminated.

Within a sterile zone, work and businesses function as usual with social distancing and infection control.
Supply chains of essential goods i.e. food, medication, and banking and routine medical activities can be resumed. To maintain the integrity of sterile zones, immediate testing must be carried out in suspected cases or contacts. Mass gatherings, group activities and movement in and out of sterile zones is prohibited. To prevent migration of cases from contaminated areas, the buffer zone acts to seal borders to prevent cross contamination and governance remains similar to contaminated zones (Figure 4).

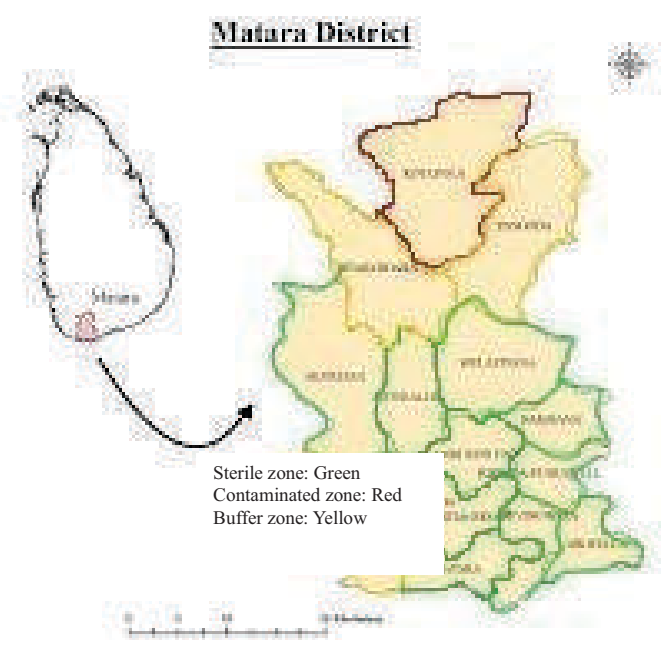

Figure 4: Depiction of the zones

In governance, not only health but social and economic aspects were also considered. The implementation of governance was simplified as health related and non-health related governance so that all sectors may comprehend it. Governance within a contaminated zone remains stringent. A curfew is to be maintained. Travel is reserved for essential services and transporting of goods systematically. With large parts of the country likely to open post-lockdown, resources can be diverted to those in high-risk areas, with a focus on vulnerable groups. Masks must be worn as recommended by medical experts. Home quarantine of contacts, vigilant surveillance of contacts and communitylevel testing is to be continued in this zone.

Strict border crossing criteria is essential to prevent sterile zone contamination. We suggest regulation of 
movement of food, fuel, electricity and water suppliers, health staff and military staff as paramount in maintaining robustness of this proposed strategy. All attempts must be made to contain essential service staff in the same zone, if travel is necessary, a standard operating procedure must be developed with stakeholder consultation.

Five key principles are proposed to extend the sterile zones and shrink contaminated zones across the nation. It includes contact tracing, widespread testing, isolation on case confirmation, quarantine, and proper social distancing with infection control. This permits rapid status identification and extension of surface areas defined as 'sterile'.

The implementation of this strategy as mentioned, is based on each divisional secretariat and its team consists of the divisional level officers representing line ministries. Each officer should be allocated a particular responsibility. The support of the medical officer of health $(\mathrm{MOH})$ and team is also imperative as the expert key stakeholder in the control mechanism and also as the monitoring team.

Whilst the day to day activities will be conducted and monitored by the team at the DS, identification of zones and further instructions will be given by the main Task Force and the National COVID-19 Centre to ensure the accuracy and the reliability of the process. This will be reviewed by the COVID-19 Centre on a regular basis. Based on information from each divisional secretariat changes in the strategy control and administrative changes will be taken accordingly.

\section{Strengths and the impact of the intervention}

Only high-risk areas will remain under lockdown, while uncontaminated zones resume near normalcy. The proposal is methodical, merging low-risk zones and allows case tracking should lockdowns in smaller zones be necessary. This reduces the burden on government in surveillance and essential service provision. The government can focus on high-risk zones and on those most vulnerable. Societal damage is minimized as people return to their communities in an organised manner. In uncontaminated regions, people can resume work, provide for their families and regain financial stability.

This concept was put forward on 4 April 2020 to His excellency the president of Sri Lanka as the basis of a possible transition strategy for Sri Lanka. The introduction of this initial concept simultaneous to the other strategies which were put forward created a discussion amongst the stakeholders as to the strategies that must be carried out to proceed further.

Following its presentation to the Presidential Task Force at the National COVID-19 Centre, it resulted in an inter-sectoral discussion as to the best possible methods of transition. Whilst considering the administrative, legal and other aspects, curfew was gradually lifted in low risk areas. As a result, the country is gradually normalizing and restoring normal lifestyle whilst maintaining strict control measures to maintain control of the disease.

\section{Challenges}

The key difficulties faced were identifying the most suitable zoning strategy and zone size. Whilst a DS division is able to function as an independent unit, to maintain curfew, a 'police division' may be more suitable. DS remains a relatively large area and may not be justifiable to lockdown an entire DS, compared to a Grama-Niladhari division (GND), which would have a more acceptable case: land area ratio for lockdown. This approach is data driven, but adaptable to advice from experts and any real-time evidence.

\section{Conclusions}

Current evidence supports our strategy as a pioneering theory in COVID-19 control. This concept of 'green-zoning' has been cited in by the World Economic Forum (5) and to the best of our knowledge, in another paper of Spanish origin (6), which was released following the GMOA's strategy proposal. Effective employment of this strategy could control COVID-19 as it is dynamic to the constantly evolving status, with zoning flexibility. The guiding principle using surgical theatres as an 
example, can be adopted in other LMICs facing economic and social adversities of extended lockdowns.

We have developed this scientific, data-driven strategy in liaison with medical experts, lessons learnt from other nations and best available global evidence. This strategy can be improved further with intersectoral experts. We recommend this strategy be initiated in line with WHO recommendations in a phased, stepwise manner with constant assessment of epidemiological risk and socioeconomic benefit.

\section{Author Declaration}

Acknowledgements: We would like to acknowledge the assistance given by the Government of Sri Lanka, in giving an opportunity to present the strategy and the efforts taken by the Presidential Task Force in combining the various strategies presented.

Author contributions: AP: Development and presentation of exit strategy; SA: Initiation and development of the concept, and presentation of exit strategy; writing the article; NdeB: Assisted in development of exit strategy and writing the article; BK: Assisted in collating data and writing the article; NDS: Coordination during development of the exit strategy; SF: Coordination during the development of the exit strategy and collating data; HA: Coordination during the development of the exit strategy; $\mathrm{CD}$ and SK: Assisted in writing the article; KF: Assisted in writing the article and collating data; PC: Coordination during the development of exit strategy.

\section{References}

1. Xu S \& Li Y. Beware of the second wave of COVID19. The Lancet 2020; 395(10233): 1321-1322. DOI: 10.1016/S0140-6736(20) 30845-X.

2. Leung K, Wu J, Liu D, Leung G. First-wave COVID19 transmissibility and severity in China outside Hubei after control measures, and second-wave scenario planning: a modelling impact assessment. The Lancet 2020; 395 (10233): 1382-1393. DOI: 10.1016/SO140-6736(20)30746-7.

3. WHO. COVID Strategy 2020. Available from: https://www.who.int/docs/default-source/ corona viruse/covid-strategy-update-14 april2020. pdf?sfvrsn=29da3ba0_17. Accessed 14 April 2020.

4. Ferguson N, Laydon D, Nedjati-Gilani G, Imai N, Ainslie K, Ghani A. Report 9: Impact of nonpharmaceutical interventions (NPIs) to reduce COVID-19 mortality and healthcare demand. Imperial College COVID-19 Response Team. Available from: https://www.imperial.ac.uk/ media/imperial-college/medicine/sph/ide/gidafellowships/Imperial-College-COVID19-NPImodelling-16-03-2020.pdf. Accessed 25 April 2020.

5. VoxEU \& CEPR. Green zones: a mathematical proposal for how to exit from the COVID-19 lockdown. World Economic Forum 2020. Available from: https://www.weforum.org /agenda/2020/04/ green-zones-a-mathematical-proposal-for-how-toexit-from-the-covid-19-lockdown-ec3ea698f2/ Accessed 25 April 2020.

6. Oliu-Barton M, Pradelski B, Attia L. Exit strategy: from self-confinement to green zones. EsadeEcPolCenter for Economic Policy \& Political Economy. Available from: https:// www.esade.edu/ itemsweb/wi/research/ecpol/EsadeEcPol_Insigth6_ Exit_Strategy.pdf. Accessed 25 April 2020. 